\title{
Systematic investigation of co-crystallization properties of triacylglycerols containing palmitic and oleic acids in relation with palm oil dry fractionation
}

\author{
Véronique Gibon ${ }^{1}$ and Sabine Danthine ${ }^{2}$ \\ ${ }^{1}$ Desmet Ballestra Group NV \\ ${ }^{2}$ Université de Liège
}

April 28, 2020

\begin{abstract}
Due to its unique triacylglycerol composition, palm oil has the particularity of being semi-solid at room temperature. Major fatty acids are palmitic (P) and oleic (O) types, tripalmitin (P3), oleo-dipalmitin (P2O) and palmito-diolein (PO2) being the most abundant tri-saturated, mono-unsaturated and di-unsaturated triacylglycerols. Palm oil is also the most fractionated oil worldwide, mostly in multi-step operations. Dry fractionation is a process that combines crystallization and separation of partially crystallized oil; in the case of palm oil, the main triacylglycerols involved are obviously P3, P2O and PO2. Crude palm oil is made up of symmetrical and asymmetric isomers and, more particularly, contains POP and OPP in a fixed ratio. This ratio may sometimes be modified during the refining process. Adverse effects of excessive OPP content affect the dry fractionation process and are also reflected in the crystallization properties of the produced solid and liquid fractions. It is therefore fundamental to understand at a molecular level the interactions involved. This paper details and compares the binary phase diagrams of several systems: PPP-POP, PPP-OPP; PPP-POO, POP-POO, OPP-POO and POP-OPP, obtained by combining differential scanning calorimetry and variable temperature powder X-ray diffraction. Co-crystallization properties are analyzed in dynamic mode (heating after quenching) and after tempering (few months stabilization at room temperature). The ternary phase diagrams $\mathrm{PPP} / \mathrm{POP} / \mathrm{POO}$ and $\mathrm{PPP} / \mathrm{OPP} / \mathrm{POO}$ give a complementary representation in terms of isothermal melting lines. Better understanding of these molecular interactions is critical for perspicacious carrying out of the palm oil dry fractionation process.
\end{abstract}

\section{Hosted file}

Text - PPP POP OPP POO versus palm oil dry fractionation Gibon V. and Danthine S..docx available at https : //authorea.com/users/307437/articles/438422-systematic-investigation-of-co-crystallizationproperties-of-triacylglycerols-containing-palmitic-and-oleic-acids-in-relation-with-palmoil-dry-fractionation

\section{Hosted file}

Figures - PPP POP OPP POO versus palm oil dry fractionation Gibon V. and Dantine S..docx available at https: //authorea.com/users/307437/articles/438422-systematic-investigation-of-co-crystallizationproperties-of-triacylglycerols-containing-palmitic-and-oleic-acids-in-relation-with-palmoil-dry-fractionation

\section{Hosted file}

Tables - PPP POP OPP POO versus palm oil dry fractionation Gibon V. and Danthine S..doc available at https://authorea.com/users/307437/articles/438422-systematic-investigation-of-co-crystallization- 
properties-of-triacylglycerols-containing-palmitic-and-oleic-acids-in-relation-with-palmoil-dry-fractionation 